\title{
Pregnancy Outcomes in the Tofacitinib Safety Databases for Rheumatoid Arthritis and Psoriasis
}

\author{
Megan E. B. Clowse ${ }^{1} \cdot$ Steven R. Feldman $^{2} \cdot$ John D. Isaacs $^{3} \cdot$ Alexandra B. Kimball $^{4}$. \\ Vibeke Strand $^{5}$ - Richard B. Warren ${ }^{6}$. Daniel Xibillé ${ }^{7} \cdot$ Yan Chen $^{8}$. \\ Donald Frazier ${ }^{9} \cdot$ Jamie Geier $^{10} \cdot$ James Proulx $^{9} \cdot$ Amy Marren $^{8}$
}

Published online: 9 June 2016

(c) The Author(s) 2016. This article is published with open access at Springerlink.com

\begin{abstract}
Introduction Tofacitinib is an oral Janus kinase inhibitor for the treatment of rheumatoid arthritis (RA), and is being investigated for the treatment of psoriasis. Both conditions can present in women of child-bearing potential, but pregnancy was an exclusion and discontinuation criterion in tofacitinib randomized controlled trials (RCTs) because of the unknown effects of tofacitinib on mother and child. Tofacitinib is a small molecule that has the potential to cross the placenta.
\end{abstract}

Electronic supplementary material The online version of this article (doi:10.1007/s40264-016-0431-z) contains supplementary material, which is available to authorized users.

Amy Marren

Amy.marren@pfizer.com

1 Duke University School of Medicine, Durham, NC, USA

2 Department of Dermatology, Wake Forest University School of Medicine, Winston-Salem, NC, USA

3 The NIHR Newcastle Biomedical Research Centre, Newcastle University and Newcastle upon Tyne Hospitals NHS Foundation Trust, Newcastle upon Tyne, UK

4 Department of Dermatology, Massachusetts General Hospital and Harvard Medical School, Boston, MA, USA

5 Division of Immunology/Rheumatology, Stanford University School of Medicine, Palo Alto, CA, USA

6 Dermatology Centre, University of Manchester, Manchester Academic Health Science Centre, Manchester, UK

7 Hospital General de Cuernavaca, Cuernavaca, Morelos, Mexico

8 Pfizer Inc, 500 Arcola Rd, Collegeville, PA 19426, USA

9 Pfizer Inc, Groton, CT, USA

10 Pfizer Inc, New York, NY, USA
Objective The objective was to report outcomes of pregnancy cases identified through April 2014 from tofacitinib RA/psoriasis RCTs, RA post-approval non-interventional studies, and spontaneous adverse-event reporting.

Methods Pregnancy outcomes were categorized as follows: healthy newborn, medical termination, fetal death, congenital malformation, spontaneous abortion, or pending/lost to follow-up.

Results Out of 9815 patients, 1821 female patients of child-bearing age were enrolled in the RA/psoriasis RCTs; 47 women became pregnant, including 33 who received tofacitinib monotherapy, 13 who received combination therapy with methotrexate (RA patients only), and one patient whose therapy was still blinded. No fetal deaths were reported. One congenital pulmonary valve stenosis (monotherapy, $n=1$ ), seven spontaneous abortions (monotherapy, $n=4$; combination therapy, $n=3$ ), and eight medical terminations (monotherapy, $n=4$; combination therapy, $n=3$; blinded therapy, $n=1$ ) were identified. Remaining cases reported healthy newborns $(n=25)$ or were pending/lost to follow-up $(n=6)$. Fortyfour cases of paternal exposure to tofacitinib were reported (monotherapy, $n=43$; combination therapy, $n=1$ ), including five spontaneous abortions (monotherapy, $n=4$; combination therapy, $n=1$ ), 23 healthy newborns, and 16 pending/lost to follow-up.

Conclusions The pregnancy outcomes reported in this small number of RA/psoriasis patients appear similar to those observed in the general population and in patients treated with biologic therapies for inflammatory diseases. However, definitive conclusions cannot be drawn, and pregnancy outcomes in patients receiving tofacitinib will continue to be monitored. 


\section{Key Points}

Tofacitinib is an oral Janus kinase inhibitor for the treatment of rheumatoid arthritis (RA), and is being investigated for the treatment of psoriasis.

There are currently no adequate or well-controlled studies of tofacitinib or any disease-modifying antirheumatic drug in pregnant women.

Pregnancy outcomes reported in the tofacitinib RA and psoriasis safety databases appear similar to those observed in the general population and in patients treated with biologic therapies for inflammatory diseases.

\section{Introduction}

Tofacitinib is an oral Janus kinase (JAK) inhibitor for the treatment of rheumatoid arthritis (RA) [1-7]; it is also being investigated for the treatment of psoriasis [8-10]. Clinical programs have studied tofacitinib dosed at $1-30 \mathrm{mg}$ twice daily (BID) and $20 \mathrm{mg}$ once daily (QD) for RA, and 5-50 mg BID and $60 \mathrm{mg}$ QD for psoriasis, and dosages of 5 and $10 \mathrm{mg}$ BID have been brought forward to phase 3 studies for both RA and psoriasis. Tofacitinib $5 \mathrm{mg}$ BID was approved by the US Food and Drug Administration (FDA) in 2012 for the treatment of moderately to severely active RA and has since been approved in many other countries [11]. More recently, this year, tofacitinib $11 \mathrm{mg}$ QD (extended-release tablet) was also approved by the FDA for the treatment of moderately to severely active RA.

Pre-clinical animal studies have shown that tofacitinib was teratogenic in rats and rabbits when given at exposures 146 times and 13 times greater than the human dosage of $5 \mathrm{mg}$ BID [11]. Teratogenic effects included membranous ventricular septal defects and skeletal/cranial malformations or variations. There was an observed increase in postimplantation loss $(56.8 \%$ in rats dosed at $100 \mathrm{mg} / \mathrm{kg}$ vs. $4.0 \%$ in the control group) and a decrease in the number of viable fetuses and mean fetal body weight.

Although RA and psoriasis are conditions that may be present in women of child-bearing potential, there are currently few adequate or well-controlled studies of disease-modifying antirheumatic drugs (DMARDs), and none of tofacitinib, in pregnant women [12]. Tofacitinib is a small molecule that could potentially cross the placenta, and because of the unknown risks of tofacitinib to mother and child, randomized controlled trial (RCT) protocols excluded pregnant patients and required the use of highly effective contraception by women of child-bearing potential. Furthermore, study medication was required to be discontinued in any patients who became pregnant. Nevertheless, pregnancies did occur and outcomes were recorded and followed up, where possible. Additionally, some clinical trials involved the use of methotrexate (MTX), a known teratogen associated with a range of embryopathies [13].

The aim of this analysis was to describe reported pregnancies and their outcomes from tofacitinib RA and psoriasis clinical safety databases up to April 2014. In addition, RA post-approval non-interventional studies and spontaneous adverse-event (AE) reporting were also analyzed.

\section{Methods}

Cases of pregnancy were identified from a search of AEs in Pfizer's safety databases through April 30, 2014, including the tofacitinib clinical development programs in RA and psoriasis, post-approval non-interventional studies, and spontaneous $\mathrm{AE}$ reporting from all countries around the world where tofacitinib is marketed. Pregnancy cases from post-marketing non-interventional studies in the USA and Canada were reported via the Organization of Teratology Information Specialists (OTIS) registry, a not-for-profit organization monitoring medications, chemicals, and other exposures during pregnancy [14].

Patients enrolled in the RA and psoriasis RCTs had to be aged at least 18 years at the time of informed consent (see Electronic Supplementary Material 1 for a list of studies from the RA and psoriasis clinical development programs). If consent to follow pregnancy to outcome was provided by the patient (or patient's partner), then sites were responsible for gathering information on pregnancy outcomes through normal AE reporting on pregnancy follow-up forms. In addition, clinical sites were requested to provide additional information based on projected outcome date. In the absence of follow-up information, a case would not be updated with outcome and would be recorded as 'lost to follow-up'. Pregnancy cases reported in this analysis of RCTs included females who received study medication at the time of conception and/or during the course of pregnancy. In addition, cases of identified paternal exposure to tofacitinib were included in this study. All cases were reviewed for any pregnancy-related outcomes and categorized as either healthy newborn (including preterm births and newborns with low birth weight), medical termination, fetal death (defined as death after 20 weeks' gestation), congenital malformation, spontaneous abortion, or pending/lost to follow-up (including refusal of consent to follow-up). 


\section{Results}

\subsection{Pregnancy Cases}

Of the 9815 RA and psoriasis patients enrolled in the Pfizer-sponsored tofacitinib RCTs, 47 women became pregnant (Table 1).

A total of 6192 patients with 16,839 patient-years of tofacitinib exposure were enrolled in RA RCTs, from whom 31 cases of pregnancy $(2.4 \%)$ were identified in 1309 female patients aged 18-44 years (Table 1). Tofacitinib exposure occurred within the first trimester in all but two cases, where exposure occurred in the second and third trimester, respectively.

A total of 3623 patients with 5204 patient-years of tofacitinib exposure were enrolled in psoriasis RCTs, from whom 16 cases of pregnancy $(3.1 \%)$ were identified among 512 female patients aged 18-44 years (Table 1). Tofacitinib exposure occurred during the first trimester for all cases (Table 1).

\subsection{Pregnancy Outcomes in RA Patients}

A total of 31 cases were reported in the RA RCTs: 18 cases $(58.1 \%)$ in patients receiving tofacitinib monotherapy, and 13 cases $(41.9 \%)$ in those treated with tofacitinib and MTX (Fig. 1a; Table 2). One pregnancy resulting in a spontaneous abortion was identified in a 34-year-old female receiving placebo in combination with MTX $20 \mathrm{mg}$.

\subsubsection{RA Patients on Tofacitinib Monotherapy}

Among the 18 pregnancy cases identified in RA patients who received tofacitinib monotherapy, one congenital malformation (pulmonary valve stenosis; $5.6 \%$ ) was identified in a 32-year-old patient with hypertension treated with the angiotensin II receptor antagonist losartan (50 mg QD), who received tofacitinib $5 \mathrm{mg}$ BID. Estimated duration of in utero tofacitinib exposure was 35 days, gestational age at delivery was 38 weeks,

Table 1 Patient characteristics for women who received tofacitinib and became pregnant in the RA and psoriasis clinical trials

\begin{tabular}{|c|c|c|}
\hline Characteristic & RA & Psoriasis \\
\hline Patients with reports of pregnancy $\left(n / N\right.$ of female patients aged $\left.18-44^{\mathrm{a}}\right)$ & $31 / 1309(2.4 \%)$ & $16 / 512(3.1 \%)$ \\
\hline Median age (range), years ${ }^{\mathrm{b}}$ & $31(22-40)$ & $27(19-40)$ \\
\hline Study medication ( $n ; \%$ of identified cases) & $\begin{array}{l}\text { Tofacitinib monotherapy (18; } \\
58.1 \%) \\
\text { Tofacitinib + MTX (13; } \\
41.9 \%)\end{array}$ & $\begin{array}{l}\text { Tofacitinib monotherapy }(16 \text {; } \\
100 \%)\end{array}$ \\
\hline \multicolumn{3}{|l|}{ Pregnancy outcomes, $n$ ( $\%$ of identified cases) } \\
\hline Fetal death & $0(0.0 \%)$ & $0(0.0 \%)$ \\
\hline Congenital malformation & $1(3.2 \%)$ & $0(0.0 \%)$ \\
\hline Spontaneous abortion & $6(19.4 \%)$ & $1(6.3 \%)$ \\
\hline Healthy newborn & $16(51.6 \%)$ & $9(56.3 \%)$ \\
\hline Medical termination & $4(12.9 \%)$ & $4(25.0 \%)$ \\
\hline Lost/pending to follow-up & $4(12.9 \%)$ & $2(12.5 \%)$ \\
\hline $\begin{array}{l}\text { Range of total time on study medication at time of pregnancy identification, } \\
\text { range, days }{ }^{c}\end{array}$ & $28-1344$ & 21-349 \\
\hline \multicolumn{3}{|l|}{ Duration of in utero study medication exposure, days ${ }^{\mathrm{d}}$} \\
\hline Range & $7-244$ & $14-43$ \\
\hline$\leq 90$ days & 29 cases & 16 cases \\
\hline$>90$ and $\leq 180$ days & 1 case & 0 case \\
\hline$>180$ days & 1 case & 0 case \\
\hline
\end{tabular}

MTX methotrexate, $R A$ rheumatoid arthritis

${ }^{\text {a }}$ Enrolled in RA or psoriasis clinical trials

b Based on 30 and 15 patients with data, respectively

c Data available for $n=26$ and $n=10$ patients in the RA and psoriasis clinical trials, respectively

${ }^{\mathrm{d}}$ Based on when pregnancy occurred and when the subject was discontinued from the study drug 
Fig. 1 Overview of pregnancy outcomes in RA and psoriasis clinical development programs. Pregnancy outcomes as a percentage of cases identified in patients with RA (a) and psoriasis (b)
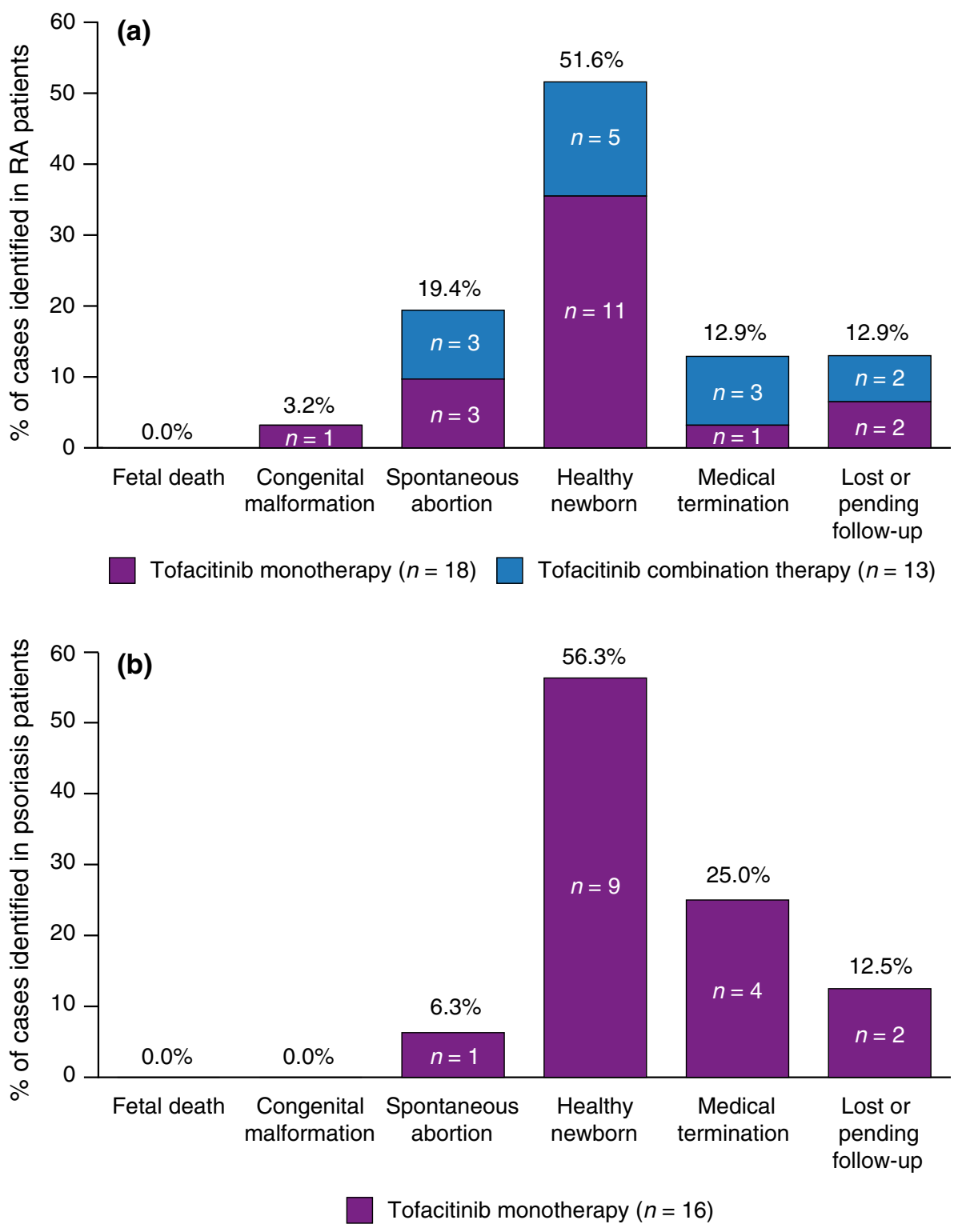

and no delivery complications or fetal distress were reported. Infant birth weight was $3.2 \mathrm{~kg}$, length $48 \mathrm{~cm}$, and the Apgar score was 8 at $1 \mathrm{~min}$ and 9 at 5 min postdelivery.

Three spontaneous abortions (16.7\%) (5 mg BID, $n=1 ; 10 \mathrm{mg}$ BID, $n=1 ; 15 \mathrm{mg} \mathrm{BID}, n=1)$ and one medical termination $(5.6 \%)$ (10 mg BID) were reported. Eleven patients $(61.1 \%)$ gave birth to healthy newborns (5 mg BID, $n=6 ; 10 \mathrm{mg}$ BID, $n=5$ ); among the five healthy newborns reported in patients receiving tofacitinib $10 \mathrm{mg}$ BID, one low-birth-weight infant $(2.1 \mathrm{~kg})$ was delivered at 37 weeks (10th percentile at 37 weeks $=2.5 \mathrm{~kg}$ [15]), and one infant was delivered preterm (35 weeks' estimated gestational age; $2.4 \mathrm{~kg}$; 10th percentile at 35 weeks $=2.2 \mathrm{~kg}[15]$ ).

\subsubsection{RA Patients on Tofacitinib/MTX Combination Therapy}

Among the 13 pregnancies identified in patients who received tofacitinib in combination with MTX, three spontaneous abortions $(23.1 \%)$ occurred, all in patients receiving tofacitinib $10 \mathrm{mg}$ BID (MTX $20 \mathrm{mg}, n=1$; MTX unspecified dose, $n=2$ ). Three medical terminations $(23.1 \%)$ were reported: two in patients dosed with tofacitinib $5 \mathrm{mg}$ BID (MTX $20 \mathrm{mg}, n=1$; MTX unspecified dose, $n=1$ ) and one in a patient who received tofacitinib $10 \mathrm{mg}$ BID and an unspecified dose of MTX. Five patients $(38.5 \%)$ gave birth to healthy newborns, of whom one was treated with $5 \mathrm{mg}$ QD (MTX $2.5 \mathrm{mg}$ ), two were treated with $5 \mathrm{mg}$ BID (MTX $17.5 \mathrm{mg}, n=1$; MTX unspecified 
Table 2 Pregnancy outcomes by tofacitinib dose after maternal exposure

\begin{tabular}{|c|c|c|c|c|c|c|c|}
\hline & \multirow{2}{*}{$\begin{array}{l}\text { Median age } \\
\text { (range), years }\end{array}$} & \multirow{2}{*}{$\begin{array}{l}\text { Fetal } \\
\text { death }^{\mathrm{a}}\end{array}$} & \multirow{2}{*}{$\begin{array}{l}\text { Congenital } \\
\text { malformation }\end{array}$} & \multirow{2}{*}{$\begin{array}{l}\text { Spontaneous } \\
\text { abortion }\end{array}$} & \multicolumn{3}{|c|}{ Other outcomes } \\
\hline & & & & & $\begin{array}{l}\text { Healthy } \\
\text { newborn }\end{array}$ & $\begin{array}{l}\text { Medical } \\
\text { termination }\end{array}$ & $\begin{array}{l}\text { Pending/lost to } \\
\text { follow-up }\end{array}$ \\
\hline $\begin{array}{l}\text { RA clinical trials: tofacitinib } \\
\quad \text { monotherapy all doses }(n=18)\end{array}$ & $31(22-39)$ & 0 & 1 & 3 & $11^{\mathrm{b}}$ & 1 & 2 \\
\hline $\begin{array}{l}\text { Tofacitinib monotherapy } 5 \mathrm{mg} \text { BID } \\
(n=8)\end{array}$ & $27(22-39)$ & 0 & 1 & 1 & 6 & 0 & 0 \\
\hline $\begin{array}{l}\text { Tofacitinib monotherapy } 10 \mathrm{mg} \text { BID } \\
(n=9)\end{array}$ & $32(27-39)$ & 0 & 0 & 1 & $5^{\mathbf{b}}$ & 1 & 2 \\
\hline $\begin{array}{l}\text { Tofacitinib monotherapy } 15 \mathrm{mg} \text { BID } \\
(n=1)\end{array}$ & 31 & 0 & 0 & 1 & 0 & 0 & 0 \\
\hline $\begin{array}{l}\text { RA clinical trials: tofacitinib all } \\
\text { doses }+ \text { MTX all doses }(n=13)\end{array}$ & $32(22-40)^{\mathrm{d}}$ & 0 & 0 & 3 & 5 & 3 & 2 \\
\hline $\begin{array}{l}\text { Tofacitinib } 5 \mathrm{mg} \text { QD + MTX } 2.5 \mathrm{mg} \\
(n=1)\end{array}$ & 34 & 0 & 0 & 0 & 1 & 0 & 0 \\
\hline $\begin{array}{l}\text { Tofacitinib } 5 \mathrm{mg} \text { BID + MTX } \\
10 \mathrm{mg}(n=1)\end{array}$ & 22 & 0 & 0 & 0 & 0 & 0 & 1 \\
\hline $\begin{array}{l}\text { Tofacitinib } 5 \mathrm{mg} \text { BID + MTX } \\
17.5 \mathrm{mg}(n=1)\end{array}$ & 29 & 0 & 0 & 0 & 1 & 0 & 0 \\
\hline $\begin{array}{l}\text { Tofacitinib } 5 \mathrm{mg} \text { BID + MTX } \\
20 \mathrm{mg}(n=1)\end{array}$ & 24 & 0 & 0 & 0 & 0 & 1 & 0 \\
\hline $\begin{array}{l}\text { Tofacitinib } 5 \mathrm{mg} \text { BID }+ \text { MTX } \\
\text { unspecified dose }(n=2)\end{array}$ & $34(31-36)$ & 0 & 0 & 0 & 1 & 1 & 0 \\
\hline $\begin{array}{l}\text { Tofacitinib } 10 \mathrm{mg} \text { BID + MTX } \\
20 \mathrm{mg}(n=1)\end{array}$ & 28 & 0 & 0 & 1 & 0 & 0 & 0 \\
\hline $\begin{array}{l}\text { Tofacitinib } 10 \mathrm{mg} \text { BID }+ \text { MTX } \\
\text { unspecified dose }(n=5)\end{array}$ & $36(32-40)^{\mathrm{d}}$ & 0 & 0 & 2 & 1 & 1 & 1 \\
\hline $\begin{array}{l}\text { Tofacitinib } 20 \mathrm{mg} \text { QD }+ \text { MTX } 25 \mathrm{mg} \\
(n=1)\end{array}$ & 25 & 0 & 0 & 0 & 1 & 0 & 0 \\
\hline $\begin{array}{l}\text { Psoriasis clinical trials: tofacitinib } \\
\text { monotherapy all doses }(n=16)\end{array}$ & $27(19-40)^{\mathrm{d}}$ & 0 & 0 & 1 & 9 & 4 & 2 \\
\hline $\begin{array}{l}\text { Tofacitinib monotherapy } 5 \mathrm{mg} \text { BID } \\
(n=2)\end{array}$ & $34(31-36)$ & 0 & 0 & 0 & 1 & 1 & 0 \\
\hline $\begin{array}{l}\text { Tofacitinib monotherapy } 10 \mathrm{mg} \text { BID } \\
(n=13)\end{array}$ & $27(19-40)^{\mathrm{d}}$ & 0 & 0 & 1 & 8 & 2 & 2 \\
\hline Blinded therapy $^{\mathrm{c}}(n=1)$ & 26 & 0 & 0 & 0 & 0 & 1 & 0 \\
\hline
\end{tabular}

$B I D$ twice daily, $M T X$ methotrexate, $Q D$ once daily, $R A$ rheumatoid arthritis

a Death after 20 weeks' gestation

b Includes two preterm/low-birth-weight newborns

c Study still ongoing and blinded

${ }^{\mathrm{d}}$ Includes one patient for whom age was not known

dose, $n=1$ ), one was treated with tofacitinib $10 \mathrm{mg}$ BID (MTX unspecified dose), and one was treated with tofacitinib $20 \mathrm{mg}$ QD (MTX $25 \mathrm{mg}$ ). Two patients who received tofacitinib in combination with MTX were pending/lost to follow-up (tofacitinib $5 \mathrm{mg}$ BID/MTX $2.5 \mathrm{mg}, n=1$; tofacitinib $10 \mathrm{mg}$ BID/MTX unspecified dose, $n=1$ ).

\subsection{Pregnancy Outcomes in Psoriasis Patients}

Sixteen pregnancies were reported among patients in the psoriasis RCTs; each patient received tofacitinib as monotherapy (Table 2). One spontaneous abortion $(6.3 \%)$ was reported (tofacitinib $10 \mathrm{mg}$ BID) and four medical terminations $(25.0 \%)$ were reported (tofacitinib $5 \mathrm{mg} \mathrm{BID}, n=1$; tofacitinib $10 \mathrm{mg}$ BID, $n=2$; blinded therapy, $n=1$ ) (Fig. 1b; Table 2). Nine women $(56.3 \%)$ gave birth to healthy newborns (5 mg BID, $n=1 ; 10 \mathrm{mg}$ BID, $n=8$ ). No fetal deaths or congenital malformations were identified. Two outcomes $(12.5 \%)$ of patients receiving tofacitinib $10 \mathrm{mg}$ BID were pending/lost to follow-up. 


\subsection{Pregnancy Outcomes Identified in Non- interventional Safety Studies and Spontaneous AE Reporting (up to April 2014)}

In addition to the cases identified in the tofacitinib RCTs (described in Fig. 1; Tables 1 and 2, and above), one spontaneous report was received (pending/lost to follow-up case in a patient receiving tofacitinib monotherapy) and two pregnancies were reported in non-interventional studies: one spontaneous abortion, which occurred in a 33-yearold patient treated with tofacitinib in combination with MTX (10 mg), and one pending/lost to follow-up case, which occurred in a patient receiving tofacitinib monotherapy.

\subsection{Overview of Paternal Exposure in RA and Psoriasis Clinical Trials}

Forty-four cases of paternal exposure to tofacitinib were identified in RA ( $n=3$; age 35-42 years) and psoriasis ( $n=41$; age $22-54$ years) RCTs. In the 39 cases where sufficient details were provided, exposure occurred around the time of conception and within the first trimester. Two $(66.7 \%)$ of the RA cases were healthy newborns; the other resulted in a spontaneous abortion in a patient who received tofacitinib $10 \mathrm{mg}$ BID and MTX $7.5 \mathrm{mg}$. In addition, two healthy newborns were identified in tofacitinib RA clinical trials, in patients who did not receive tofacitinib: one in a patient who received placebo and MTX, and one in a patient who received adalimumab.

Of the 41 cases reported in patients with psoriasis, 21 $(51.2 \%)$ were healthy newborns, four $(9.8 \%)$ were spontaneous abortions, and $16(39.0 \%)$ were pending/lost to follow-up.

\section{Discussion}

This study reports pregnancies from a large database of patients in the tofacitinib clinical development program $(n=9815)$. Forty-seven cases ( 31 and 16 cases in RA and psoriasis patients, respectively) were reported after maternal exposure; there were 25 healthy newborns, no reports of fetal death, seven spontaneous abortions, eight medical terminations, one congenital malformation (pulmonary valve stenosis), and six cases pending/lost to follow-up. Paternal exposure to tofacitinib was also reported in 44 pregnancies fathered by men in the RA and psoriasis RCTs, resulting in 23 healthy newborns, five spontaneous abortions, and 16 cases pending/lost to follow-up. One spontaneous abortion and two pending/lost to follow-up cases were reported in the non-interventional safety studies and through spontaneous AE reporting (up to April 2014).
The observed frequencies of congenital malformations ( $2 \%)$ and spontaneous abortions (15\%) across the RA and psoriasis RCTs are consistent with background risks in the general population and in patients with RA or psoriasis. In the general population of the USA, the background risk for major birth defects is about $3 \%$, and for spontaneous abortions is $15-20 \%[16,17]$. Similar, or slightly lower, background risks for spontaneous abortion have been reported in other regions (UK 20\% [18], Denmark $13.5 \%$ [19], China $7.9 \%$ [20], and Brazil $14.0 \%$ [21]). In RA patients, studies have reported a background risk of $4.3 \%$ for major congenital malformations and birth defects [22], with an increased risk for pregnancy complications dependent on RA activity [23-25]. In patients with moderate to severe psoriasis, an increased risk for spontaneous and induced abortions, macrosomic newborns, and premature rupture of membranes was reported [26, 27].

In the current analysis of RA RCTs, 13 of 31 reported pregnancies occurred in patients receiving concomitant MTX treatment, a known teratogen and abortofacient $[13,28]$. The current US prescribing information specifies that MTX is contraindicated during pregnancy. Furthermore, a clear dose threshold has been reported for teratogenic effects of MTX, with increased risk of abnormalities during the first trimester with all doses but particularly with dosages greater than $10 \mathrm{mg}$ per week [13, 28-30]. In the 13 pregnancy cases reported herein, the dose of MTX received ranged from 2.5 to $25 \mathrm{mg}$ (where specified). Published estimates from a cohort with rheumatic diseases indicated pregnancy losses of $22.5 \%$ in patients who did not receive MTX versus $42.5 \%$ for those receiving MTX [28]. These observations suggest that MTX is likely to be a confounding factor in adverse pregnancy outcomes reported in the tofacitinib RA RCTs; however, our data are currently too limited to support MTX as the sole cause of the adverse pregnancy outcomes reported in patients on combination therapy.

Studies of biologic therapies have reported similar pregnancy outcomes after maternal exposure to those observed in this study [31-37]. Published data indicate an association between risk of preterm delivery and increased disease activity [23]. Here, two preterm births were reported for tofacitinib among the 16 RA healthy newborns and no cases were identified in the psoriasis RCTs.

Tofacitinib is a small molecule (free-base form 312.4 Daltons) that has the potential to cross the placenta. Preclinical animal studies have demonstrated that treatment with tofacitinib led to a reduced number of viable fetuses and a reduced fetal body weight in rats [11]. In addition, tofacitinib was shown to be secreted in the milk of lactating rats [11]. As the tofacitinib clinical development program was designed to limit any risks to pregnant mother and child, there are currently no adequate and well-controlled 
studies in pregnant or nursing women. The current US prescribing information for tofacitinib specifies that tofacitinib should be used during pregnancy only if the potential benefit justifies the potential risk to the fetus [11].

There are limitations to the currently reported data. Although results were drawn from relatively large clinical trial databases, this was not a prospective analysis and a relatively small number of pregnancies were identified. Additionally, outcomes were not available for six (12.8\%) of the reported pregnancies after maternal exposure, and limited information is available on the exact date of conception and gestational age in several cases. Finally, clearcut associations between the effects of tofacitinib on pregnancy outcomes cannot be drawn because of confounders, such as underlying RA and psoriasis disease activity, concomitant treatments, and other concurrent medical conditions.

\section{Conclusion}

Based on these limited clinical data, unintentional exposure to tofacitinib during conception/pregnancy does not appear to be associated with an increased risk to the fetus when compared with risks identified in the general population and specifically reported in RA and psoriasis patients. However, definitive conclusions cannot be drawn and pregnancy outcomes in patients receiving tofacitinib will continue to be monitored in RCTs, through routine pharmacovigilance, and via a post-approval safety study with the OTIS registry. As pregnancy was an exclusion criterion in the tofacitinib clinical development program, it is expected that pregnancy outcomes may occur more frequently in the post-approval setting. If exposure to tofacitinib occurs as a result of unintended pregnancy, a benefitrisk discussion should be undertaken between the patient, family, and appropriate healthcare professionals.

Acknowledgments The authors would like to thank the patients, investigators, and study teams involved in the studies reported in this analysis.

\section{Compliance with Ethical Standards}

Ethical approval and informed consent All subjects provided written informed consent, and ethics committee approval was received for all sites in the RA and psoriasis studies.

Funding The studies reported in this manuscript were sponsored by Pfizer Inc. Medical writing support for the development of this manuscript, under direction from the authors, was provided by Alice Palmer, $\mathrm{PhD}$, and Sandrine M. Dupré, $\mathrm{PhD}$, of Complete Medical Communications, and funded by Pfizer Inc.

Conflict of interest Megan Clowse is a consultant for Pfizer Inc (for a single lecture not related to the work presented in this manuscript) and UCB, and has received research grants from Janssen and Pfizer Inc. Steven R. Feldman has received consulting, research, and manuscript support from Pfizer Inc, and consulting, research, and/or speaking support from AbbVie, Amgen, Boehringer Ingelheim, Celgene, Eli Lilly, Janssen, Merck, and Novartis. John D. Isaacs is a consultant for and has received research grants from Pfizer Inc. Alexandra B. Kimball has served as a consultant and investigator for AbbVie, Amgen, Dermira, Eli Lilly, Janssen, Merck, Novartis, and Pfizer Inc, and has fellowship funding from Janssen. She also serves as an advisor to the OTIS Stelara Pregnancy registry. Vibeke Strand has received consulting fees from AbbVie, Amgen, AstraZeneca, BiogenIdec, BMS, Celgene, Corrona, Crescendo, Eli Lilly, EMDSerono, Genentech/Roche, GlaxoSmithKline, Janssen, Novartis, Pfizer Inc, Regeneron, Sanofi, UCB, and Vertex. Richard B. Warren has received grant/research support from AbbVie, Novartis, and Pfizer Inc; has served as a consultant for AbbVie, Amgen, Boehringer Ingelheim, Celgene, Eli Lilly, Janssen, Novartis, Pfizer Inc, and Xenoport; and is a member of speakers' bureaux for AbbVie, Amgen, Celgene, Eli Lilly, Janssen, Novartis, and Pfizer Inc. Daniel Xibillé has received consultancy fees from BMS and Pfizer Inc, and payment for clinical studies from AstraZeneca, BMS, GlaxoSmithKline, Janssen, and Pfizer Inc. Yan Chen, Donald Frazier, Jamie Geier, James Proulx, and Amy Marren are employees and shareholders of Pfizer Inc.

Open Access This article is distributed under the terms of the Creative Commons Attribution-NonCommercial 4.0 International License (http://creativecommons.org/licenses/by-nc/4.0/), which permits any noncommercial use, distribution, and reproduction in any medium, provided you give appropriate credit to the original author(s) and the source, provide a link to the Creative Commons license, and indicate if changes were made.

\section{References}

1. van der Heijde D, Tanaka Y, Fleischmann R, Keystone E, Kremer J, Zerbini C, et al. Tofacitinib (CP-690,550) in patients with rheumatoid arthritis receiving methotrexate: twelve-month data from a twenty-four-month phase III randomized radiographic study. Arthritis Rheum. 2013;65:559-70.

2. Burmester GR, Blanco R, Charles-Schoeman C, Wollenhaupt J, Zerbini C, Benda B, et al. Tofacitinib (CP-690,550) in combination with methotrexate in patients with active rheumatoid arthritis with an inadequate response to tumour necrosis factor inhibitors: a randomised phase 3 trial. Lancet. 2013;381:451-60.

3. Fleischmann R, Kremer J, Cush J, Schulze-Koops H, Connell $\mathrm{CA}$, Bradley JD, et al. Placebo-controlled trial of tofacitinib monotherapy in rheumatoid arthritis. $\mathrm{N}$ Engl $\mathrm{J}$ Med. 2012;367:495-507.

4. Kremer J, Li ZG, Hall S, Fleischmann R, Genovese M, MartinMola E, et al. Tofacitinib in combination with nonbiologic disease-modifying antirheumatic drugs in patients with active rheumatoid arthritis: a randomized trial. Ann Intern Med. 2013;159:253-61.

5. Lee EB, Fleischmann R, Hall S, Wilkinson B, Bradley J, Gruben $\mathrm{D}$, et al. Tofacitinib versus methotrexate in rheumatoid arthritis. N Engl J Med. 2014;370:2377-86.

6. van Vollenhoven RF, Fleischmann R, Cohen S, Lee EB, García Meijide JA, Wagner S, et al. Tofacitinib or adalimumab versus placebo in rheumatoid arthritis. N Engl J Med. 2012;367:508-19.

7. Wollenhaupt J, Silverfield J, Lee EB, Curtis JR, Wood SP, Soma $\mathrm{K}$, et al. Safety and efficacy of tofacitinib, an oral Janus kinase Inhibitor, for the treatment of rheumatoid arthritis in open-label, longterm extension studies. J Rheumatol. 2014;41:837-52. 
8. Bissonnette R, Iversen L, Sofen H, Griffiths CEM, Foley P, Romiti R, et al. Tofacitinib withdrawal and retreatment in moderate-to-severe chronic plaque psoriasis: a randomized controlled trial. Br J Dermatol. 2015;172:1395-406.

9. Papp KA, Menter MA, Abe M, Elewski B, Feldman SR, Gottlieb $\mathrm{AB}$, et al. Tofacitinib, an oral Janus kinase inhibitor, for the treatment of chronic plaque psoriasis: results from two, randomized, placebo-controlled, phase III trials. Br J Dermatol. 2015;173:949-61.

10. Bachelez H, van de Kerkhof PC, Strohal R, Kubanov A, Valenzuela F, Lee JH, et al. Tofacitinib versus etanercept or placebo in moderate-to-severe chronic plaque psoriasis: a phase 3 randomised non-inferiority trial. Lancet. 2015;386:552-61.

11. Pfizer Inc. Xeljanz prescribing information. 2014. http://labeling. pfizer.com/ShowLabeling.aspx?id=959. Accessed 26 Mar 2016.

12. Götestam Skorpen C, Hoeltzenbein M, Tincani A, Fischer-Betz R, Elefant E, Chambers C, et al. The EULAR points to consider for use of antirheumatic drugs before pregnancy, and during pregnancy and lactation. Ann Rheum Dis. 2016;75:795-810.

13. Hyoun SC, Obican SG, Scialli AR. Teratogen update: methotrexate. Birth Defects Res A Clin Mol Teratol. 2012;94:187-207.

14. Organization of Teratology Information Specialists (OTIS) registry. 2016. http://parthenonmanagementgroup.com/portfolio/ organization-of-teratology-information-specialists-otis/. Accessed 23 Mar 2016.

15. Hadlock FP, Harrist RB, Martinez-Poyer J. In utero analysis of fetal growth: a sonographic weight standard. Radiology. 1991;181:129-33.

16. American College of Obstetricians and Gynecologists. Miscarriage and molar pregnancy. 2011. http://www.lexingtonobgyn. com/webdocuments/acog/early-pregnancy-loss.pdf.

17. Rynn L, Cragan J, Correa A. Update on overall prevalence of major birth defects-Atlanta, Georgia, 1978-2005. MMWR Morb Mortal Wkly Rep. 2008;57:1-5.

18. Royal College of Obstetricians and Gynaecologists. NICE Clinical Guidelines: Ectopic pregnancy and miscarriage: diagnosis and initial management in early pregnancy of ectopic pregnancy and miscarriage. 2012. https://www.nice.org.uk/guidance/cg154. Accessed 5 May 2016.

19. Nybo Andersen AM, Wohlfahrt J, Christens P, Olsen J, Melbye M. Maternal age and fetal loss: population based register linkage study. BMJ. 2000;320:1708-12.

20. Wang X, Chen C, Wang L, Chen D, Guang W, French J. Conception, early pregnancy loss, and time to clinical pregnancy: a population-based prospective study. Fertil Steril. 2003;79: 577-84.

21. Cecatti JG, Guerra GV, Sousa MH, Menezes GM. Abortion in Brazil: a demographic approach. Rev Bras Ginecol Obstet. 2010;32:105-11.

22. Norgaard M, Larsson H, Pedersen L, Granath F, Askling J, Kieler $\mathrm{H}$, et al. Rheumatoid arthritis and birth outcomes: a Danish and Swedish nationwide prevalence study. J Intern Med. 2010;268: 329-37.
23. Bharti B, Lee SJ, Lindsay SP, Wingard DL, Jones KL, Lemus H, et al. Disease severity and pregnancy outcomes in women with rheumatoid arthritis: results from the Organization of Teratology Information Specialists Autoimmune Diseases in Pregnancy Project. J Rheumatol. 2015;42:1376-82.

24. de Man YA, Hazes JM, van der Heide H, Willemsen SP, de Groot CJ, Steegers EA, et al. Association of higher rheumatoid arthritis disease activity during pregnancy with lower birth weight: results of a national prospective study. Arthritis Rheum. 2009;60:3196-206.

25. Langen ES, Chakravarty EF, Liaquat M, El-Sayed YY, Druzin ML. High rate of preterm birth in pregnancies complicated by rheumatoid arthritis. Am J Perinatol. 2014;31:9-14.

26. Cohen-Barak E, Nachum Z, Rozenman D, Ziv M. Pregnancy outcomes in women with moderate-to-severe psoriasis. J Eur Acad Dermatol Venereol. 2011;25:1041-7.

27. Lima XT, Janakiraman V, Hughes MD, Kimball AB. The impact of psoriasis on pregnancy outcomes. $\mathrm{J}$ Invest Dermatol. 2012;132:85-91.

28. Weber-Schoendorfer C, Chambers C, Wacker E, Beghin D, Bernard N, Shechtman S, et al. Pregnancy outcome after methotrexate treatment for rheumatic disease prior to or during early pregnancy: a prospective multicenter cohort study. Arthritis Rheumatol. 2014;66:1101-10.

29. Kozlowski RD, Steinbrunner JV, MacKenzie AH, Clough JD, Wilke WS, Segal AM. Outcome of first-trimester exposure to low-dose methotrexate in eight patients with rheumatic disease. Am J Med. 1990;88:589-92.

30. Nguyen C, Duhl AJ, Escallon CS, Blakemore KJ. Multiple anomalies in a fetus exposed to low-dose methotrexate in the first trimester. Obstet Gynecol. 2002;99:599-602.

31. Vinet E, Pineau C, Gordon C, Clarke AE, Bernatsky S. Biologic therapy and pregnancy outcomes in women with rheumatic diseases. Arthritis Rheum. 2009;61:587-92.

32. Krause ML, Amin S, Makol A. Use of DMARDs and biologics during pregnancy and lactation in rheumatoid arthritis: what the rheumatologist needs to know. Ther Adv Musculoskelet Dis. 2014;6:169-84.

33. Mervic L. Management of moderate to severe plaque psoriasis in pregnancy and lactation in the era of biologics. Acta Dermatovenerol Alp Pannonica Adriat. 2014;23:27-31.

34. Ruiz V, Manubens E, Puig L. Psoriasis in pregnancy: a review (II). Actas Dermosifiliogr. 2014;105:813-21.

35. Weber-Schoendorfer C, Oppermann M, Wacker E, Bernard N, Beghin D, Cuppers-Maarschalkerweerd B, et al. Pregnancy outcome after TNF-alpha inhibitor therapy during the first trimester: a prospective multicentre cohort study. Br J Clin Pharmacol. 2015;80:727-39.

36. Horst $S$, Kane $S$. The use of biologic agents in pregnancy and breastfeeding. Gastroenterol Clin North Am. 2014;43:495-508.

37. Verstappen SM, King Y, Watson KD, Symmons DP, Hyrich KL. Anti-TNF therapies and pregnancy: outcome of 130 pregnancies in the British Society for Rheumatology Biologics Register. Ann Rheum Dis. 2011;70:823-6. 